
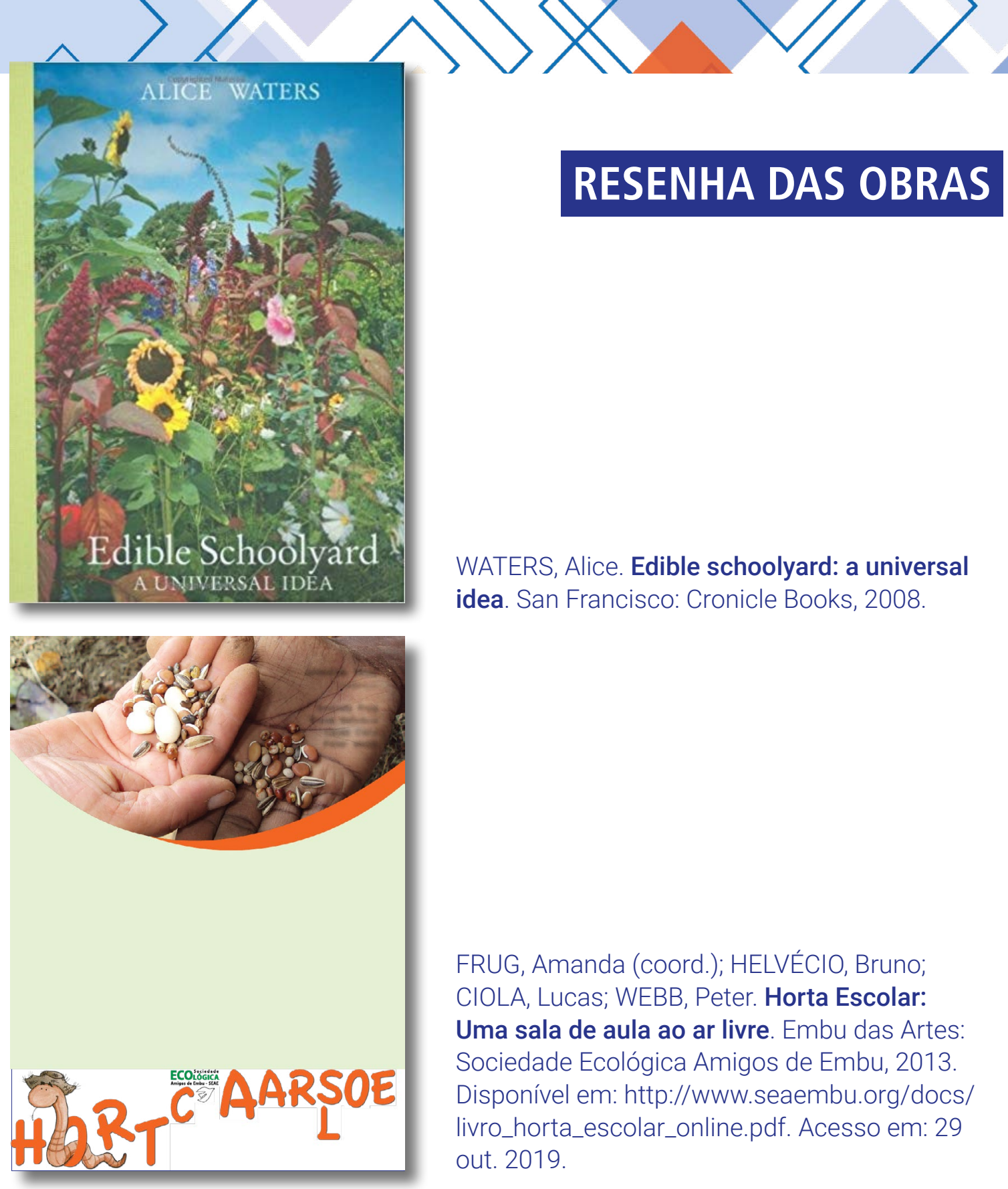

WATERS, Alice. Edible schoolyard: a universal idea. San Francisco: Cronicle Books, 2008.

FRUG, Amanda (coord.); HELVÉCIO, Bruno; CIOLA, Lucas; WEBB, Peter. Horta Escolar: Uma sala de aula ao ar livre. Embu das Artes: Sociedade Ecológica Amigos de Embu, 2013. Disponível em: http://www.seaembu.org/docs/ livro_horta_escolar_online.pdf. Acesso em: 29 out. 2019.

\title{
Alimentação e Educação: um encontro feliz
}

Há muitos anos, numa conversa em Brasília, Francisco Ansiliero, chef de cozinha do restaurante Dom Francisco, contou que participara de desafio proposto pela Empresa Brasileira de Pesquisa Agropecuária (Embrapa). Ele e quatro outros profissionais foram chamados a preparar um jantar cujo menu deveria utilizar produtos de um dos biomas brasileiros. Francisco, por sua vez, foi convidado a elaborar o cardápio com alimentos do cerrado - segundo ele, um desafio que exigia pesquisa extensiva, abrangendo geografia, história, cultura, ciências e técnicas gastronômicas. Com base em tal pesquisa, o cozinheiro deveria criar um jantar saboroso e inédito. 
Enquanto escutava a história contada por Francisco, fiquei a imaginar como desafios similares poderiam acontecer no campo da educação. Muitos anos depois de minha conversa com o chef de Brasília, acabei transferindo o desafı da Embrapa para o contexto educacional. Eu fui convidado a propor situações que poderiam funcionar como exemplos de experiências de aprendizagem autêntica, em que os alunos trabalhassem ativamente para elaborar um produto. Tal produto exigiria dos estudantes muito estudo e pesquisa, abrangendo diversas dimensões do currículo. Minhas propostas foram convertidas em programas de televisão em forma de seriado, que recebeu o nome de Desafıo Escolar, e foi transmitido pela emissora do Ministério da Educação, a TV MEC. Uma dessas propostas foi a Mesa Americana (BARATO, 2013). Alunos de ensino médio, em equipes de até oito estudantes, foram convidados a produzir um jantar com menu constituído exclusivamente por alimentos de origem americana. A versão final desse desafio pode ser encontrada no YouTube (CAMINHOS, 2010).

Sabemos muito pouco sobre a origem dos alimentos que vêm à nossa mesa. Do arroz e feijão de cada dia pouco conhecemos história, formas de plantio e colheita, processamento, armazenamento, valor nutritivo, comercialização. Mas nossa relação de saber com os alimentos poderia ser diferente. Nossas práticas sociais de alimentação não são apenas atos de necessária nutrição. Elas estão cercadas por significados, quase sempre, tácitos. Elas têm raízes históricas muito antigas. Envolvem invenções relacionadas com ciências. Refletem costumes de povos que viveram séculos ou milhares de anos antes de nós. Slobodkin (1992), no capítulo 4 de Simplicty and Complexity of Games of Intellect, Three Dinner Parties, revela aspectos culturais da alimentação humana que podem ser jogos intelectuais interessantes para tornar mais complexa ou simplificar a realidade. Alimentar-se não é apenas uma forma de atender demandas biológicas. É também uma forma de mostrar entendimentos sobre a natureza, os outros, o prazer etc. Traduzo trecho do primeiro parágrafo do citado capítulo:

O processo nutricional biológico comum se torna foco de arte e é elaborado, simplificado, ou minimizado por muitas razões, assim como o ato biológico comum de andar e correr é convertido em dança. Ao considerar o ato de jantar, podemos introduzir, de um modo simples e acessível, exemplos do que essencialmente pode ser simplificado ou tornado mais complexo (SLOBODKIN, 1992, p. 81).

Slobodkin descreve jantares em diversas sociedades para mostrar que a alimentação pode ser uma atividade que reflete costumes capazes de desvelar cultura e história em situações aparentemente banais. Mostra que alimentar-se não é apenas uma atividade biológica, mas uma elaborada forma de celebrar a vida.

Preparar alimentos e produzi-los pode ser um caminho interessante para que estudantes teçam na ação relações entre conteúdos de diversas áreas de saber. Em Mesa Americana, por exemplo, isso aconteceu com investigações que mostraram 
a relação dos alimentos nativos de nosso continente com geografia, história, economia, cultura e outros saberes. Além disso, o desafio trouxe surpresas, pois as pessoas quase sempre desconhecem que a batata inglesa é, na verdade, peruana.

Depois de desenhar Mesa Americana, continuei a me interessar por projetos que associam alimentação e educação. Dois desses projetos merecem atenção especial e são descritos em obras aqui resenhadas.

\section{Plantas, em vez de asfalto}

Edible Schoolyard: A universal idea (WATERS, 2008) é um livro que descreve o projeto cuja alma é a famosa chef de cozinha Alice Waters. Para situar a obra, convém apresentar a autora. Alice Waters formou-se na Universidade de Berkeley em Estudos Franceses. Depois, em Londres, especializou-se no método Montessori, em um instituto internacional que prepara professores para utilizarem as propostas da educadora italiana. Ela foi, durante cinco anos, professora em uma escola montessoriana de Berkeley. No entanto uma experiência na França, em estágio de Arte Culinária, mudou inteiramente os rumos da vida profissional de Alice.

Encantada com a cozinha francesa, de volta aos EUA, ela abriu o restaurante Chez Panisse. Alice vê a cozinha francesa com olhos de especialistas em Gastronomia que seguem princípios do movimento Slow Food. Em seu restaurante, ela serve alimentos orgânicos frescos, produzidos por agricultores locais. A militância de Alice por alimentos saudáveis, produzidos localmente, chama atenção da imprensa e ela costuma ser entrevistada sobre suas propostas bastante diferentes daquilo que ocorre no mundo da culinária. Em uma dessas entrevistas, a chef de cozinha de Berkeley sugeriu que os terrenos baldios da cidade fossem utilizados para produzir alimentos. Ela comentou que, em uma escola pela qual ela passava todos os dias a caminho de seu restaurante, havia uma imensa área coberta por asfalto e mato que poderia estar produzindo alimento saudável para os alunos. Aquele terreno, aparentemente abandonado, depunha contra a educação pública, um dos pilares da democracia nos Estados Unidos. Dias depois, Neil Smith, diretor da escola criticada por Alice, a Martin Luther King Jr. Middle School, convidou-a para uma visita e conversa. Neil concordava com a crítica recebida e queria ajuda para mudar o que acontecia em sua escola. A atitude do diretor surpreendeu Alice e, ao mesmo tempo, colocou a chef em situação que a obrigava a sugerir caminhos para que a escola alterasse complemente relações entre educação e alimentação. Alice aceitou o desafio, mas não sabia o que propor ao diretor da escola. Começou, então, a buscar alternativas que pudessem colocar a Martin Luther King Jr. no mapa da alimentação saudável e de uma educação que articulasse necessidades nutritivas com todas as dimensões do currículo.

A primeira preocupação de Alice foi conquistar aliados para a ideia de associar educação com alimentação saudável. Para tanto, ela organizou um evento para alunos e suas famílias no pátio da escola. A atividade foi um jantar em que as pessoas 
eram convidadas, com o apoio de funcionários do Chez Panisse, a preparar tortiIhas que seriam ali consumidas. Houve alguma demora para que pais e estudantes aceitassem o convite para colocar, literalmente, a mão na massa. Mas depois de certo tempo, mais de uma centena de estudantes e alguns pais estavam preparando tortilhas com entusiasmo. Na sequência, por áreas de saber, os professores da escola foram convidados para um jantar no Chez Panisse. Essas primeiras atividades buscaram obter interesse da comunidade escolar por programas de alimentação saudável. O diretor da escola e Alice Waters sabiam que haveria resistência, sobretudo dos professores, pois estes já estavam sobrecarregados com demandas de trabalho cada vez mais exigentes. Por isso, essas e outras atividades exploratórias demoraram cerca de dois anos. Finalmente, Neil Smith disse a Alice que havia condições para começar o projeto, pois ele contava com o apoio de uma voluntária, mãe de aluno da escola. É interessante notar que o diretor da escola e a chef de cozinha tenham colocado como condição para início do projeto a existência de voluntários que acreditassem na proposta. Assim, dois anos após a entrevista de Alice Waters com crítica ao mau aproveitamento do solo na Martin Luther King Jr., houve condições favoráveis para começar a aventura do que atualmente é conhecido como Edible Schoolyard.

Alice Waters recorreu a amigos e fornecedores do Chez Panisse, a fim de conseguir os necessários recursos para dar início ao projeto, pois o orçamento da educação em Berkeley era extremamente minguado. Com os recursos que ela conseguiu, pôde imprimir à atividade uma direção profissional. Contratou um diretor para o schoolyard [utilizo o termo em inglês, pois não encontrei em português palavra que pudesse comunicar toda a riqueza de significado da proposta desenvolvida na escola de Berkeley], David Hawkins, um britânico com muita experiência em projetos de educação não formal e com capacitação no campo da produção de alimentos orgânicos. David começou seu trabalho transformando a área escolhida para plantio em solo que poderia receber sementes. Para tanto, contratou uma escavadora para remover o asfalto e derrubar restos de construções, que não eram mais usadas pela escola. Uma das professoras levou seus alunos à área para que eles auxiliassem a limpeza do terreno, retirando as pedras que ficaram sobre o solo. Providenciou-se uma análise de solo, pois, em muitas escolas, a área em que estão construídas pode ser poluída e necessitar de tratamento prévio para atividades de plantio.

Antes da contratação de David, Alice e Neil tinham realizado várias reuniões com arquitetos, agricultores locais e engenheiros para definir o design do que viria a ser o schoolyard da Martin Luther King Jr. Tudo estava pronto para começar. Havia recursos. Havia participação de alguns professores. Havia voluntários da comunidade. E havia um profissional para dirigir o trabalho. David foi contratado no fim do semestre e logo começariam as férias de verão. Ele tomou a inciativa de convidar alunos capazes de assumir o trabalho com a terra no primeiro momento de plantio na área escolhida para o scholyard durante o recesso escolar. Com esses alunos, foi a uma área de mata para recolher material necessário à formatação de canteiros e 
construção de cercas. O trabalho na mata era muito exigente. Os alunos reclamaram. Alguns chegaram a dizer que aquela atividade deveria ser remunerada. David mudou a abordagem e converteu o corte de galhos em um jogo, dedicando parte do tempo à produção de arcos e flechas. Com a mudança, obteve maior cooperação dos estudantes. A área de plantio começava a ser desenhada. Mas David percebeu que ela não deveria ser organizada de acordo com as sugestões de arquitetos e engenheiros. O desenho do local foi se estruturando a partir de sugestões dos próprios estudantes.

\section{Alimentos do schoolyard vão à mesa}

Com a volta às aulas, o projeto começa a integrar os alunos ao cultivo do schoolyard. A ideia-mestra era oferecer aos estudantes oportunidade de aprender fazendo, em um percurso que vai da semente à mesa e, a seguir, da mesa à semente. Em tal percurso, os alunos enriquecem o solo, plantam, cultivam, colhem, preparam os alimentos e comem o que produzem. Não se trata de uma horta escolar. É muito mais que isso. É uma experiência integral no campo da alimentação, estabelecendo ligações dos alimentos com história, ciência e cultura. Mas o começo foi modesto. Ainda não havia grande variedade de vegetais cultivados. E, na primeira experiência de levar à mesa o que estava sendo produzido no solo da escola, a professora chef de cozinha dispunha apenas de couve. Nenhum outro vegetal estava maduro, então. O desafio era grande: como fazer com que crianças e adolescentes comam couve? Esther, a cozinheira chef da escola, resolveu associar couve com algum alimento disponível. Para tanto, propôs aos alunos produzir torradas com o pão que podiam encontrar na cozinha e, posteriormente, inventarem combinações de torradas com couve cozida. Os estudantes acabaram criando diversos tipos de canapés. A produção final dos estudantes foi acomodada em uma grande bandeja, colocada no centro de uma mesa do refeitório. Os alunos foram convidados a experimentar os canapés. Esther reparou que o primeiro aluno demorou certo tempo para fazer sua escolha. Ela temeu que os estudantes não se interessassem por canapés de couve. Porém o rapaz fez sua escolha e comeu com aparente prazer o canapé escolhido. A mesma situação se passou com os demais estudantes e Esther observou que a relativa demora na escolha do canapé se devia a um desejo que cada estudante tinha de comer o que produzira. Essa descoberta foi posteriormente usada como elemento motivacional em outras atividades do Edible Schoolyard.

Com o tempo, o número de diferentes vegetais plantados pelos alunos e funcionários cresceu consideravelmente. Ali, não se plantam apenas hortaliças e legumes. Plantam-se cereais, árvores frutíferas, ervas para tempero e chás, oliveiras, flores. Alguns anos depois de iniciado o projeto, foram introduzidas galinhas naquele terreno. As aves, além de livrarem as plantas de caramujos e insetos nocivos, põem ovos que passam a fazer parte dos pratos que os alunos produzem na cozinha. 
Fiz referência a vários episódios na cozinha da escola. Isso merece explicação mais detalhada. A proposta de Alice Waters não está centrada apenas no cultivo de alimentos. Também são de importância fundamental no projeto as atividades na cozinha. Os alunos preparam vários pratos com o que é cultivado no schoolyard. Para que a preparação de alimentos acontecesse de maneira profissional, Alice contratou uma chef para dirigir as atividades na cozinha. Além disso, com o auxílio de profissionais da comunidade, pais e professores, o projeto construiu uma nova cozinha quando a velha cozinha da escola foi fechada para posterior reforma. Os alunos processam alimentos produzidos na escola, assim como alimentos orgânicos fornecidos por agricultores da região. O que produzem é consumido por eles e por outros estudantes em um processo que busca formar hábitos de alimentação saudável. A diferença entre a proposta da chef de Berkeley e o que ocorria na escola é enorme. Quando ela se reuniu com Neil Smith para conversar sobre aproveitamento do terreno baldio da Martin Luther King Jr., a alimentação na escola, com a velha cozinha desativada, era constituída por refrigerantes, batatas fritas, bolachas, alimentos industrializados. Cumpre observar que uma das dimensões do privatismo na educação americana, segundo Alex Molnar (2005), é a existência de contratos das escolas públicas com fábricas de refrigerantes e indústrias alimentícias. Para Alice, defensora de alimentação saudável e dos princípios do Slow Food, era preciso mudar inteiramente a oferta de alimentação na escola. Para tanto, a existência de uma cozinha e a coordenação de uma chef comprometida com educação eram essenciais.

O livro de Alice Waters é ricamente ilustrado. Há nele abundância de fotos retratando atividades no cultivo e na preparação de alimentos. As imagens fornecem informações interessantes sobre o projeto, ressaltando uma das dimensões que a autora considera importantes na alimentação associada à educação: a beleza. A área plantada é muito bonita, com canteiros não só de hortaliças, mas também de flores. Além disso, o perímetro é cercado por árvores frutíferas e oliveiras. $\mathrm{Na}$ cozinha e no refeitório, a preocupação com estética também é evidente, incluindo detalhes de decoração com obras de artesãos e artistas de Berkeley, que doaram trabalhos para a escola. A chef da cozinha do Schoolyard incentiva a invenção de pratos atrativos e bonitos.

Os alunos comem o que produziram. Isso, como já se observou, tem óbvias virtudes motivacionais. Mas o ato de alimentar-se é entendido de maneira mais profunda pela chef de Berkeley. Ela entende que sentar-se à mesa para uma refeição dá início a encontros humanos mediados por alimentos bem-preparados. Esse é um aspecto que o criador do movimento Slow Food, Carlo Petrini, costuma sempre lembrar quando se senta à mesa com seus convidados (HONORÉ, 2005). Assim como Lawrence Slobodkin, Alice Waters entende que o ato de se alimentar pode ser um evento cultural muito significativo. À mesa, na Martin Luther King Jr., os alunos aprendem isso. 


\section{Alimentos e história}

Professores de todas as áreas da escola tecem relações entre o schoolyard e o que ensinam. Para ilustrar, recorro a um vídeo realizado pelo grupo Growing a Greener World (2010). O vídeo conta um pouco do projeto, relaciona princípios que alimentam o que ali se realiza e mostra algumas das atividades que acontecem na plantação e na cozinha. Ressalto aqui observações de um professor da escola sobre cultivo de cereais e história.

O Professor Benjamin Eichorn observa que um dos melhores ângulos para abordar a história é verificar como povos em todo o mundo, em diversas épocas, produziram seus alimentos. Isso pode estar escrito nos livros. Isso pode ser encontrado na internet. Na Martin Luther King Jr., a exploração da relação entre alimentos e história dos povos não fica restrita a um tratamento acadêmico. Ela ganha vida por meio das plantas cultivadas no sítio da escola.

No Edible Schoolyard, há uma grande variedade de plantas, oferecendo um quadro bastante rico do que se cultiva ou se cultivou em todo o planeta. Quando os alunos cuidam de um canteiro de aveia ou de milho, aprendem que esses cereais tiveram papel fundamental no Egito ou na Mesoamérica. E não aprendem isso apenas oralmente. Aprendem cuidando de todo o ciclo de reprodução e consumo dos cereais: preparando o terreno, plantando a semente, acompanhando o crescimento das plantas, colhendo, moendo e assando a farinha em pratos deliciosos.

Ao cultivar as plantas, os alunos entendem os cuidados próprios dos agricultores. No caso dos cereais, o projeto adota técnicas de moer cereais manualmente, muito parecidas com as utilizadas no início de uso de sementes de gramíneas como fonte alimentar. Assim, literalmente, os alunos põem a mão na massa. Com todos esses cuidados, compreender a importância de cereais, como o trigo, a aveia, o arroz e o milho, em diversas civilizações fica muito mais claro, mais vivo. Como diz o professor Benjamin, os alunos aprenderão para sempre a importância dos cereais na história da humanidade.

Deixo por alguns instantes o Edible Schoolyard. A importância do cultivo de plantas e domesticação de animais é um dos pontos centrais de um livro deslumbrante, After Ice: A global human history, 20,000-5000 BC (MITHEN, 2003). Nessa obra, escrita em ritmo de aventura, Steven Mithen examina o surgimento de formas de organização social até então inexistentes na história humana. After /ce enfatiza aspecto que, no geral, não é explorado pelos livros de história. Não me lembro de ter estudado, por exemplo, o que se comia no Brasil no século XVI. Não me lembro de aulas em que meus professores de história no ginásio dessem qualquer importância à dieta nos primeiros anos da Colônia. Até hoje eu gostaria de saber o que ia para o prato de um Martim Afonso de Sousa. Nos livros de história, há um registro abstrato sobre a importância de alguns alimentos americanos, como a batata, o milho e a mandioca. No entanto a saga do encontro de europeus, africanos e índios nas roças e cozinhas não integra, até hoje, conversas sobre história em nossas escolas, embora 
os primeiros cronistas tenham registrado a profunda admiração dos europeus por muitas frutas encontradas nas Américas (LEITE, 1992).

\section{Recado importante}

Os responsáveis pelo projeto Edible Schoolyard avisam: nada de pressa, nada de buscar resultados imediatos. Um projeto bem-feito, que articule produção de alimentos com cultura, história e ciência, leva tempo. É preciso ter muitos aliados, principalmente, professores e pais de alunos. É preciso investigar muito para descobrir todas as plantas que podem ser significativas para uma dada comunidade escolar. É preciso profissionais que entendam do trabalho na horta, no jardim, no pomar, na cozinha. É preciso, finalmente, ter muita imaginação para criar eventos expressivos, que deem sentido ao que se planta e ao que se come.

Na Martin Luther King Jr., o projeto levou três anos para amadurecer. A área de plantio surgiu três anos após a ideia de produzir alimentos na escola. Digo isso, para que alguém apressado não pense que uma horta com plantas de cultivo rápido pode reproduzir algo parecido com o projeto The Edible Schoolyard.

Em Berkeley, a alma de tudo é Alice Waters. Ela é uma chef famosa. Mais que famosa, é uma entusiasta pela alimentação sadia, culturalmente enraizada, fundada em produção local. Em projetos parecidos, será preciso buscar apoio de alguém que, fora da escola, tenha prestígio, e cuja voz seja ouvida. Não é possível encontrar uma Alice Waters em cada esquina, mas é possível envolver gente da área de restaurantes que tenha entusiasmo por educação. Uma figura assim é essencial para mobilizar governo e comunidade para obter recursos: dinheiro, adubo, sementes, ferramentas, profissionais competentes etc.

\section{Hortas escolares, ecologia e alimentação saudável}

Ao escolher a obra de Alice Waters para resenha, entendi que seria necessário selecionar também algum texto brasileiro que abordasse experiências de associação entre alimentação saudável e educação, capaz de oferecer um contraponto nacional à experiência americana. Em um levantamento em livrarias, não consegui encontrar qualquer livro atual que pudesse ser resenhado. Tive, então, que recorrer à internet, para verificar se haveria alguma obra sobre o tema, publicada digitalmente. Acabei encontrando um livro muito interessante, disponível para cópia e leitura gratuitas. Ele descreve projetos realizados em escolas do município paulista de Embu das Artes.

Horta Escolar: Uma sala de aula ao ar livre (FRUG, 2013) é obra que narra diversas experiências de educação ecológica no município de Embu, com destaque para as hortas escolares destinadas a:

Ampliar os horizontes da escola, expandir os quintais, terrenos e paisagens, promover o contato direto das crianças com ambientes naturais, facilitar a aprendizagem ao ar livre, vivencial, lúdica, com a natureza, valorizar e estimular a livre criatividade de professores e educandos, a troca de saberes (FRUG, 2013, p.10). 
Cerca de 20 escolas da cidade plantaram hortas, mas o livro escolheu narrar o que aconteceu nos três casos de maior sucesso no período de 2008 a 2011. Plantar no quintal da escola foi um desejo que decorreu da participação dos educadores no Projeto Fonte, desenvolvido pela Sociedade Ecológica Amigos de Embu. Tais educadores passaram por um processo de capacitação em educação ambiental, coordenaram a atuação de alunos em atividades fora de salas de aula (em bosques, parques, matas), integraram movimentos para promover agricultura urbana e começaram a se interessar pelo plantio de hortas em suas escolas.

As hortas escolares em unidades educacionais de Embu foram, na maior parte dos casos, iniciativas de professores entusiasmados com os benefícios de projetos que associassem alimentação e educação. Em termos de objetivos, o que aconteceu em Embu é muito parecido com o que vimos em Berkeley. Porém os projetos são bastante diferentes. Em Berkeley, a proposta é mais abrangente e insiste na ideia de que todo o ciclo de produção e consumo do alimento produzido na escola tenha participação efetiva dos alunos no campo de cultivo e na cozinha. Em Embu, as atividades estiveram mais voltadas para o cultivo. A proposta brasileira dependeu muito do entusiasmo de professores comprometidos com o meio ambiente e ganhou mais chance de sucesso quando os gestores da escola também se comprometeram com a horta escolar. Não houve, no caso brasileiro, participação de figuras públicas, como Alice Waters.

A experiência brasileira compartilha diversas características com a americana. Apesar de ter se denominado horta escolar, a área de plantio incluiu árvores frutíferas e flores. Preocupações estéticas aconteceram nos dois casos. E a questão da falta de recursos tem paralelos entre Berkeley e Embu, embora em nosso país não se tenha conseguido arrecadar fundos expressivos, como acontece na escola da Califórnia. Cultivo de alimento no quintal da escola é atividade que não é reconhecida como pedagógica para fins de recursos. Nos orçamentos-programas da educação não há lugar para compra de ferramentas agrícolas, sementes, implementos agrícolas, luvas de proteção. Também não há previsão de contratação de profissional que possa se responsabilizar em tempo integral pela área cultivada, nem um chef que coordene atividades experimentais na cozinha da escola. Alice Waters resolveu isso contratando, com recursos obtidos externamente, um diretor para o schoolyard e uma chef de cozinha. Nas escolas brasileiras, isso foi mais difícil, sobrecarregando professoras que entusiasticamente garantiram a existência da horta em suas escolas ou, em alguns casos, conquistaram a simpatia de caseiros da escola para o trabalho na horta, assim como merendeiras.

Em Horta Escolar, há muita informação útil para educadores interessados em plantar alimentos nos quintais da escola. Há, por exemplo, explicações bastante completas de como realizar compostagem para a produção de adubo orgânico. Há também informações muito completas sobre como desenvolver um minhocário. Outras informações de muita utilidade são explicações de como escorar a terra fértil, em camadas de "lasanha", nos canteiros. 
Na obra de Amanda Frug, ganham destaque testemunhos dos 25 professores que foram entrevistados em pesquisa sobre as hortas escolares de Embu. Esses docentes falam de atividades que desenvolveram e de como articularam cultivo de alimentos com várias dimensões do currículo. É interessante acompanhar tais depoimentos para avaliar o que pode ser feito em uma horta escolar por crianças que frequentam a primeira fase do ensino fundamental. Na Martin Luther King Jr., os alunos são estudantes da fase final do ensino fundamental e podem trabalhar a terra com relativa autonomia. Nas escolas de Embu, as crianças precisaram de mais assistência e apoio e não trabalharam a terra da mesma forma que os adolescentes da escola de Berkeley.

O livro de Alice Waters conta uma história em que cultivo da terra e preparação de alimentos integram-se com diversos saberes que os alunos devem desenvolver em sua educação. A linguagem não utiliza jargão pedagógico. Tem a leveza de textos que, sem utilizar terminologia de livros de didática, abordam a educação. O livro de Amanda Frug é uma narrativa de experiência com um jargão muito próprio da corporação dos pedagogos. Isso, às vezes, torna a leitura pesada para educadores que apreciam linguagem mais leve, mais literária. Além disso, o livro reflete concepções hegemônicas no campo da literatura pedagógica, utilizando, em várias partes, uma conceituação que separa os conteúdos de aprendizagem em teoria e prática. No prefácio da obra, a Professora Cláudia Maria Bógus ressalta passagem do livro que aponta finalidades do projeto: "vivenciar a teoria, desenvolver habilidades com a prática, utilizar os quintais e sistemas agroecológicos como meios curriculares". Esse modo de ver as atividades da horta escolar aparece diversas vezes no livro, seja em narrativas da autora, seja em depoimentos dos professores. Na experiência inspirada por Alice Waters não emerge tal cisão entre teoria e prática. Cabe reparar que o par antitético teoria/prática desconhece o trabalho de cultivo de plantas como atividade que facilita a elaboração de conceitos a partir da experiência. Esse não é um caminho de vivenciar a teoria, mas de elaborar saberes científicos com base na empiria. Apesar de considerar o equívoco de rotular atividades na horta escolar como prática, entendo que Horta Escolar é obra importante para educadores que queiram embarcar em aventuras de associar alimentação com todas as dimensões do currículo escolar. Por isso recomendo esse livro a professores e gestores de escolas de todos os níveis, que queiram integrar alimentação saudável aos percursos de aprendizagem.

\section{Princípios da educação associada à produção de alimentos}

O livro de Alice Waters formula em uma de suas páginas (WATERS, 2008, p. 43, tradução nossa) conjunto de princípios que, de certa forma, coincidem com os projetos de horta escolar de escolas de Embu, descritos por Amanda Frug. Traduzi e sintetizei tais princípios como segue:

- Alimento é matéria de estudo. Área de plantio, cozinha e cantina devem integrar-se ao objetivo acadêmico da escola, de tal modo que ecologia e gastronomia deem vida a todas as matérias, da escrita à leitura, das ciências às artes. 
- A escola deve fornecer alimento para todos os alunos. Da pré-escola ao ensino médio, os alunos devem receber um alimento completo e delicioso todos os dias. Boa alimentação é um direito, não um privilégio. Fornecê-la todos os dias estabelece uma relação positiva dos alunos com a saúde, com a comunidade, com o meio ambiente.

- A escola deve apoiar a agricultura local. As cantinas escolares devem comprar alimento fresco da estação, produzido de maneira autossustentável por agricultores e sitiantes locais, não só por razões de saúde e educação, mas também para fortalecer a economia de produção agrícola de alimentos na região.

- Os alunos devem aprender fazendo. A educação manual, na qual os próprios alunos fazem o trabalho nos canteiros e na cozinha, desperta os sentidos e abre as mentes, tanto para as matérias que estudam como para o mundo que os cerca.

- A beleza é uma linguagem. Um ambiente preparado com beleza, em que se pensou deliberadamente em tudo, dos caminhos do sítio aos pratos nas mesas, diz aos alunos que nós nos importamos com deles (we care).

\section{Observação final}

As obras aqui resenhadas foram escolhidas para animar educadores a concretizarem projetos que associem alimentação saudável a educação. Fiz isso porque não encontrei número significativo de pesquisas sobre o tema, nem livros mais encorpados que abordem o cultivo de alimentos como laboratório que pode ter desdobramentos importantes em termos de motivação e melhor entendimento de que 0 ato de nutrição tem história e consequências que podem tornar a educação mais deliciosa. Como reparam os educadores de Embu, com base em suas experiências de cultivo nos quintais escolares: "escola com horta é mais feliz".

\section{Referências}

BARATO, Jarbas Novelino. Mesa americana: desafio escolar. In: BARATO, Jarbas Novelino. [Blog] Boteco Escola. [S. I.], 31 jan. 2013. Disponível em: https://jarbas. wordpress.com/050-desafio-mesa-americana. Acesso em: 4 out. 2019.

CAMINHOS da Escola: desafio escolar. [S.I.]: TV Escola, 2010.

Série Desafio Escolar. Disponível em: https://www.youtube.com/ watch?v=wUiYLz1SwGk\&t=199s. Acesso em 6 out. 2019.

EDUCAÇÃO pela natureza. In: BARATO, Jarbas Novelino. [Blog] Boteco Escola. [S. I.], [2012?]. Disponível em: https://jarbas.wordpress.com/2012/03/15/ educacao-pela-natureza/. Acesso em: 29 out. 2019. 
